\title{
AUSTRALIAN AND NEW ZEALAND STANDARD \\ CLASSIFICATION OF OCCUPATIONS (ANZSCO): THE IMPACT OF A TRANS-TASMAN CLASSIFICATION ON LABOUR MARKET DATA
}

\author{
Andrew Hancock
}

Statistics New Zealand

\begin{abstract}
The introduction of the Australian and New Zealand Standard Classification of Occupations (ANZSCO) into statistical collections, particularly the 2006 Census of Population and Dwellings, has enabled the first real comparison of occupation data using a consistent standard framework between Australia and New Zealand. The paper discusses the issues of introducing a harmonised classification into statistical collections and the impact for time-series and comparability of occupation data. Issues related to what to include in the classification structure, to ensure consistency in skill levels and to establish a framework that is practical for both countries to produce occupation data on will be examined. This paper will also discuss whether ANZSCO meets the need as a standard framework and introduces a strategy for ongoing maintenance and ensuring relevance and consistency moving into the future. In addition, commentary on the relationship with the 2008 International Standard Classification of Occupations will be provided.
\end{abstract}

\section{Introduction}

In September 2006, Statistics New Zealand released the Australian and New Zealand Standard Classification of Occupations (ANZSCO). This was the culmination of a four year development project with the Australian Bureau of Statistics (ABS) and the Australian Department of Employment and Workplace Relations (DEWR). The development of ANZSCO stemmed from the agreed policy between the ABS and Statistics New Zealand to work towards developing harmonised statistical classifications.

Introducing a new trans-Tasman classification provides a basis for standardised collection, analysis and dissemination of occupation data for Australia and New Zealand. The additional benefit of developing a joint occupation classification is the ability to produce a more up-to-date, relevant and conceptually sound classification.

\section{Background to the Development of ANZSCO}

In order to move to a harmonised classification, Statistics $\mathrm{NZ}$ recognised the need to engage users of occupation classifications and data to discuss the viability of developing a joint classification. A stakeholder workshop was held in 2001. The outcomes from that workshop were that:

The similarities between the Australian and New Zealand labour markets are now seen as more significant than any differences. Increased transTasman migration, the development of an increasingly homogenous labour market and the similarity in education and training practices have all created an environment far more conducive to developing a harmonised classification;
- The participants at the workshop indicated that other than some time-series concerns, there were no significant impediments to the $\mathrm{ABS}$ and Statistics NZ proceeding to develop a harmonised occupation classification by 2006 .

- The participants acknowledged that there were a wide range of advantages to harmonisation including the extra resourcing that the ABS would provide, the ability to produce a more up-to-date, relevant and conceptually sound classification and the need for easier analysis of trans-tasman labour market data.

The timeframe for undertaking the development was initially dependent on (a) the ABS timeframe for revising the Australian Standard Classification of Occupations Second Edition (ASCOSE), and (b) the timeframe for the redevelopment of the International Standard Classification of Occupations (ISCO) by the International Labour Office.

It should be noted that since World War Two, Statistics $\mathrm{NZ}$ had based its standard occupation classification on the ISCO concepts and structure, modified to New Zealand conditions. With the ILO indicating that release of a revised ISCO was planned for 2008, both the ABS and Statistics New Zealand deemed it appropriate to proceed on developing ANZSCO in time for the 2006 Census of Population and Dwellings in both countries, rather than wait for ISCO. This tied in with the ABS ten-yearly review process for ASCO and provided another advantage in that preceding ISCO would enable any ANZSCO developments to feed into the ISCO-08 development. Classifications experts from both Statistics $\mathrm{NZ}$ and the ABS have been involved in providing advice on the ISCO developments to ensure alignment between ANZSCO and ISCO. 
Having obtained stakeholder agreement to undertake the harmonisation project, a project team was set up comprising representatives from Statistics NZ, the ABS and DEWR. In addition stakeholder advisory groups were established in each country to assist with the development of ANZSCO and provide advice on concepts and content.

The advisory groups are

- $\quad$ the ANZSCO Reference Group - which is a group of the key stakeholders who contribute to establishing the concepts, definitions and content of the classification. This group understands the key principles of the classification, and use it in a variety of forms including using statistical data produced from the classification;

- the External Advisory Group - which is a group of stakeholders comprising users of the classification and its data, plus industry organisations who can help clarify the content of a particular occupation eg tasks or skills;

- the Internal Advisory Group - which is a group of business units within Statistics New Zealand which collect and output occupational data.

Both Statistics NZ and the ABS recognised the need to have stakeholder buy-in to the benefits of a harmonised classification and actively worked with stakeholders to establish mechanism for implementing ANZSCO upon completion of the project. The biggest concern for New Zealand stakeholders was the major disruption to occupational time-series data

\section{Development of ANZSCO}

The starting point for developing ANZSCO was getting agreement between all parties on the fundamental concepts to be applied. Statistics NZ and the ABS agreed to retain the existing concepts and basic principles that had existed with the previous classifications - the New Zealand Standard Classification of Occupations (NZSCO) and the Australian Standard Classification of Occupations (ASCO). These two classifications fundamentally utilised the principles of ISCO by using skill level and skill specialisation as the primary concepts for classifying occupations and jobs. This means that ANZSCO utilises the primary concept of skill as the main criteria for grouping jobs and occupations together. Skill is defined as the ability to competently perform the tasks associated with an occupation.

The definitions of the key concepts used in ANZSCO are:

Job - a job is defined as asset of tasks designed to be performed by one person for an employer in return for pay or profit. Jobs are then grouped together to form an occupation.

Occupation - an occupation is a set of jobs that require the performance of similar or identical sets of tasks.

Skill Level - is defined as a function of the range and complexity of the set of tasks performed in a particular occupation, the greater the complexity of the tasks the greater the skill level. Skill level is measured by:

- the level or amount of formal education and training;

- the amount of previous experience in a related occupation;

- the amount of on-the-job training

Skill level is really based on the qualifications required for the occupation as aligned with the NZ Register of Quality Assured Qualifications. ANZSCO details what is deemed to be the minimum requirement for competent performance of an occupation. The skill level statements are not a prescriptive/definitive statement that the person performing the occupation must have that qualification, they are a guide only.

There are five skill levels applied to ANZSCO. These are:

- $\quad$ Skill Level 1 - University degree or above; or at least five years experience;

- $\quad$ Skill Level 2 - NZ Register Diploma, or at least three years experience;

- $\quad$ Skill Level 3 - NZ Register Level 4, or at least three years experience;

- $\quad$ Skill Level 4 - NZ Register Level 2 or 3, or at least one years experience;

- $\quad$ Skill Level 5 - NZ Register Level 1, or just on-thejob training.

The skill levels basically determine which Major Group (1 digit level) of ANZSCO an occupation might be classified in eg all occupations generally requiring a university degree are in Major Group 2 Professionals. (Skill Levels are defined in full in Appendix 2.)

Skill Specialisation - which is defined as a function of the:

- $\quad$ knowledge required;

- $\quad$ tools and equipment used;

- materials worked on;

- goods or services produced or provided.

Skill specialisation is used more at the lower levels of the classification to refine the structure and group occupations.

\section{Classification Structure}

ANZSCO is a five level hierarchical classification. This means that occupations (which are at the six digit level) can be grouped into broader groupings as you move up the classification structure. Conversely, major groups can be broken down into more detailed levels.

The following table details the classification structure: 


\begin{tabular}{llc}
\hline Code & Title & Number \\
\hline 1 Digit & Major Group & 8 \\
2 Digit & Sub-Major Group & 43 \\
3 Digit & Minor Group & 97 \\
4 Digit & Unit Group & 358 \\
6 Digit & Occupation & 998 \\
\hline
\end{tabular}

NB: There is no 5 digit level.

The eight ANSCO Major Groups (1 digit level) are:

\begin{tabular}{cl}
\hline Code & Title \\
\hline 1 & Managers \\
2 & Professionals \\
3 & Technical and Trades Workers \\
4 & Community and Personal Service Workers \\
5 & Clerical and Administrative Workers \\
6 & Sales Workers \\
7 & Machinery Operators and Drivers \\
8 & Labourers \\
\hline
\end{tabular}

\section{Operationalising the Classification}

ANZSCO currently has 998 occupations in the structure. This is supported by a coding index of over 16,000 job titles, so each occupational category in the structure may have any number of job titles assigned to it.

The occupation listed in the classification is given a six digit code number. The code is a sequential code based on the hierarchical structure. An example is:

133511 Production Manager (Forestry)

where

the first digit (1) represents Major Group 1 Managers;

the first and second digits (13) represents the SubMajor Group 13 Specialist Managers;

the first, second and third digits (133) represents the Minor Group 133 Construction, Distribution and Production Managers

the first, second, third and fourth digits (1335) represents the Unit Group 1335 Production Managers.

The Major Groups are named based upon historic or international practice, intuitive or logical appeal or stakeholder requirements.

The occupation titles that are included in the structure usually represent the most commonly understood title for that particular occupation or set of jobs. This is constrained by ensuring consensus between Australian and New Zealand stakeholders as a title may be appropriate in one country and not the other. Sometimes joint titles are used eg Naval Architect (Aus)/Marine Designer (NZ).

Occupations may also list alternative titles which are titles that are of almost equal importance or meaning but may be less used. For example Production Manager (Forestry) has the alternative title of Forest Manager. This enables recognition of titles in the structure without giving them their own category.

Additionally, occupations can include specialisations which are titles that are deemed to be a subset of the primary occupation but not significant to be a category in their own right. This also provides an opportunity to identify emerging occupation titles as they can be listed as specialisations but may not warrant their own category at the moment. An example is 841311 Forestry Worker which has specialisations of Tree Planter and FireLookout.

\section{Criteria for Inclusion as a Separate Occupation}

For an occupation to be included in its own right in the classification structure it must meet certain criteria. These are:

- That at least 100 persons report employment in the occupation in the New Zealand Census of Population and Dwellings;

- That the skill requirements make it unique/distinct from other occupations in both Australia and New Zealand;

- That the tasks and duties make it unique/distinct from other occupations in both Australia and New Zealand;

- That it is statistical feasible to collect information about the occupation ie that people will actually respond with that title in a statistical survey or administrative collection in both Australia and New Zealand;

- That it is an occupation that can be legally performed in either Australia, or New Zealand or both;

- That there is stakeholder consensus in both Australia and New Zealand to include the occupation;

- Maintaining time-series and international comparability;

- That there is stakeholder demand - subject to the above criteria

- NB: Occupations are not included just to meet skill shortages or immigration requirements.

As a starting point for establishing the structure of ANZSCO, SNZ and the ABS pooled together a master list of occupations from NZSCO and ASCO. Duplicates were removed and then differences were examined to ascertain whether the occupations existed in either country, and what was the content and naming used in each country. New occupations identified by stakeholders and through census analysis then enlarged the list and 
through an iterative process a basic listing of occupations for inclusion was established.

Where the occupations were agreed upon the next step was to compare the tasks and skill requirements in each country for them. This involved comprehensive consultation with industry experts and training organisations. The biggest issue in this process was the identification of the formal qualifications and then ascertaining whether the skill level was the same for both countries.

\section{Skill Level Issues}

Obtaining consensus on skill levels for occupations was a time-consuming process. It required the project team to be sure they were talking about the same occupational content and then looking to see what the requisite minimum qualifications were. The determination of skill level was hampered by:

- Australian Industrial Wage Awards compared to New Zealand Employment Contracts;

- $\quad$ Australian Qualifications Framework (AQF) not being aligned with the New Zealand Register of Quality Assured Qualifications (NZ Register);

- The proliferation of education providers in New Zealand such that like qualifications could not necessarily be treated as like;

\section{- $\quad$ Skills creep}

The Australian wage awards often had entrenched and dated skill requirements embedded in them. This meant that in many instances Australia seemed behind New Zealand in the skill requirements for many occupations particularly in the trades and machine operators.

With neither the AQF nor the NZ Register being fully aligned it was often difficult to agree to what the equivalent was, or rather what could be an agreed skill level for occupations. Where one country had a higher skill level than the other, the project team generally went with the higher skill level but this was more on a case by case basis, and subject to where in the classification an occupation was to be placed. The goal was to try and have the four digit unit groups at the same skill level this was not always achievable as occupations were often grouped together for intuitive reasons.

A key concern for both agencies in developing ANZSCO was being confident that the skill level information supplied for any particular occupation was, in fact, the most appropriate information. An increasing trend that was noticed was for many occupations to be given higher qualifications than was expected, as a means for education providers, to enhance their profiles and obtain greater funding. An example might be where an education provider provided a degree level qualification for an occupation which industry indicated was only at diploma level or below. A related issue to this was whether the project team should accept higher qualifications, where industry indicated that the skill level was changing or whether it was better to stay with the current, generally accepted qualifications. The approach taken was to go with the current, generally accepted qualifications. Occupations that were known to be having their skill levels developed to a higher qualification were noted for future reviews.

\section{Data Issues}

A comparison of data for the 2006 Censuses in both countries at ANZSCO Major Group level is contained in Appendix Three. This basically shows that both countries had a consistent distribution pattern based on actual population counts.

However when this data is turned into a percentage breakdown (as shown in Appendix Four), New Zealand had higher percentages than Australia in Managers and Labourers. This is due to the allocation of farming occupations into these two major groups, whereas in the NZSCO structure, all farming occupations were in a single major group. Again under the percentage breakdown the distribution trend for both countries is similar.

It should be noted that the tables included in appendices four and five do not include counts for residual categories.

2006 Census of Population and Dwellings counts for ANZSCO at the occupation level show a large proportion of occupations that actually fall below the New Zealand threshold of 100 persons employed to warrant inclusion in the classification structure. In fact 193 occupation categories out of 998 were below the New Zealand threshold. The biggest proportion of these occurred in Minor Group 253 Medical Practitioners.

\section{Time-series Issues}

Moving to a trans-Tasman classification meant that for New Zealand users of the New Zealand Standard Classification of Occupations, and users of occupation data, a massive time-series disruption would take place. For Australian users, the move from the Australian Standard Classification of Occupations (ASCO) to ANZSCO was a bit less disruptive.

To alleviate the New Zealand concerns, the 2006 Census of Population and Dwellings was dual-coded to both NZSCO99 and ANZSCO. This meant that the coding index of around 16,000 job titles that is used for processing the census responses needed both classification codes assigned to each job title in the file.

Attempts were made to align the two countries coding indexes but because of operationally constraints caused by the different coding tools and methodologies used, a complete alignment to create one trans-Tasman coding index is not possible. The key step taken was to at least ensure that like responses were coded consistently. 
Analysis of intercensal data (1991-2006) based on NZSCO99 Major Groups shows a generally consistent trend across all major groups. Agricultural occupations have consistently decreased in the period. Major Group 7 Trades Workers has shown an increase in 2006 due to a large increase in both Carpenters and Builders.

The biggest growth occupation in the 1991 to 2006 period is Technical Representative with an increase of over 25,000 persons. This represents an increase in the number of persons involved in computer sales.

In analysing the top thirty occupations by population count in both Australia and New Zealand censuses, an interesting comparison can be made. Sixteen occupation categories appearing in the top thirty were the same for each country. Australia had the biggest proportion (10) of its top thirty occupations coming from Major Group 5 Clerical and Administrative Workers. New Zealand had the biggest proportion (8) of its top thirty occupations coming from Major Group 1 Managers.

\section{8/2009 Update to ANZSCO}

Statistics New Zealand, in conjunction with the Australian Bureau of Statistics, has undertaken an update to ANZSCO to refresh the classification in time for the 2011 Census of Population and Dwellings.

The update:

is a joint minor update of ANZSCO and is intended to be completed by 31 st March 2009; is only adding or deleting occupations at the six digit level. Unit groups (four digit levels) would remain unchanged unless there was an essential need to amend (either delete, add or rename);

will investigate skill levels that are known to be of concern but occupations which require a skill level change will only be moved within Minor Groups. Skill level changes which identify that an occupation needs to be moved across Major
Groups will be noted and actioned at the next major review;

will minimise time-series disruption wherever possible;

will conclude in March 2009 and there will be no additional structural changes after 31st March 2009 until the 2011 Censuses have been completed and/or when the next update or major review takes place for 2016.

\section{International Standard Classification of Occupations Commentary}

The International Labour Office (ILO) has been undertaking an updating of the International Standard Classification of Occupations (ISCO), which was last reviewed and released in 1988.

For Statistics New Zealand there are no issues with ISCO08 in terms of concepts or structure, as Statistics New Zealand has been fortunate to have had a high level of involvement in the classification development. This has ensured New Zealand needs are generally met. The ANZSCO development has clearly fed into the ISCO development as well, particularly in the coverage of ICT occupations.

The ILO is completing the writing of definitions with a view to publishing the completely revised ISCO08 early 2009.

\author{
Author \\ Andrew Hancock \\ Classifications and Standards \\ Statistics New Zealand \\ Private Bag 4741 \\ Christchurch \\ Andrew.Hancock@stats.govt.nz
}

\section{Appendix 1: Comparison Table of NZSCO99 - ANZSCO Major Groups}

\begin{tabular}{llll}
\hline \multicolumn{2}{c}{ NZSCO99 Major Groups } & & \multicolumn{1}{c}{ ANZSCO Major Groups } \\
\hline 1 & Legislators, Administrators and Managers & 1 & Managers \\
2 & Professionals & 2 & Professionals \\
3 & Technicians and Associate Professionals & 3 & Technicians and Trades Workers \\
4 & Clerks & 4 & Community and Personal Service Workers \\
5 & Service and Sales Workers & 5 & Clerical and Administrative Workers \\
6 & Agriculture and Fishery Workers & 6 & Sales Workers \\
7 & Trades Workers & 7 & Machinery Operators and Drivers \\
8 & Plant and Machinery Operators and Assemblers & 8 & Labourers \\
9 & Elementary Occupations (inc Residuals) & & \\
\hline
\end{tabular}

NB: There is not a direct correlation between the NZSCO99 and ANZSCO Major Groups. The above table merely shows the Major Groups from each classification in numeric sequence 


\section{Appendix 2: ANZSCO Skill Level Definitions}

\section{$\underline{\text { Skill Level } 1}$}

Occupations at Skill Level 1 have a level of skill commensurate with a bachelor degree or higher qualification. At least five years of relevant experience may substitute for the formal qualification. In some instances relevant experience and/or on-the-job training may be required in addition to the formal qualification.

\section{$\underline{\text { Skill Level } 2}$}

Occupations at Skill Level 2 have a level of skill commensurate with one of the following:

\section{- $\quad$ NZ Register Diploma or}

- AQF Associate Degree, Advanced Diploma or Diploma.

At least three years of relevant experience may substitute for the formal qualifications listed above. In some instances relevant experience and/or on-the-job training may be required in addition to the formal qualification.

\section{$\underline{\text { Skill Level } 3}$}

Occupations at Skill Level 3 have a level of skill commensurate with one of the following:

- $\quad$ NZ Register Level 4 qualification

- AQF Certificate IV or

- AQF Certificate III including at least two years of on-the-job training.
At least three years of relevant experience may substitute for the formal qualifications listed above. In some instances relevant experience and/or on-the-job training may be required in addition to the formal qualification.

\section{$\underline{\text { Skill Level } 4}$}

Occupations at Skill Level 4 have a level of skill commensurate with one of the following:

- $\quad$ NZ Register Level 2 or 3 qualification or

- $\quad$ AQF Certificate II or III.

At least one year of relevant experience may substitute for the formal qualifications listed above. In some instances relevant experience may be required in addition to the formal qualification.

\section{Skill Level 5}

Occupations at Skill Level 5 have a level of skill commensurate with one of the following:

- $\quad$ NZ Register Level 1 qualification

- AQF Certificate 1 or

- compulsory secondary education.

For some occupations a short period of on-the-job training may be required in addition to or instead of the formal qualification. In some instances, no formal qualification or on-the-job training may be required.

\section{Appendix 3: 2006 Australian and New Zealand Census data by ANZSCO Major Groups (excluding Residual Categories) - Population Comparison}

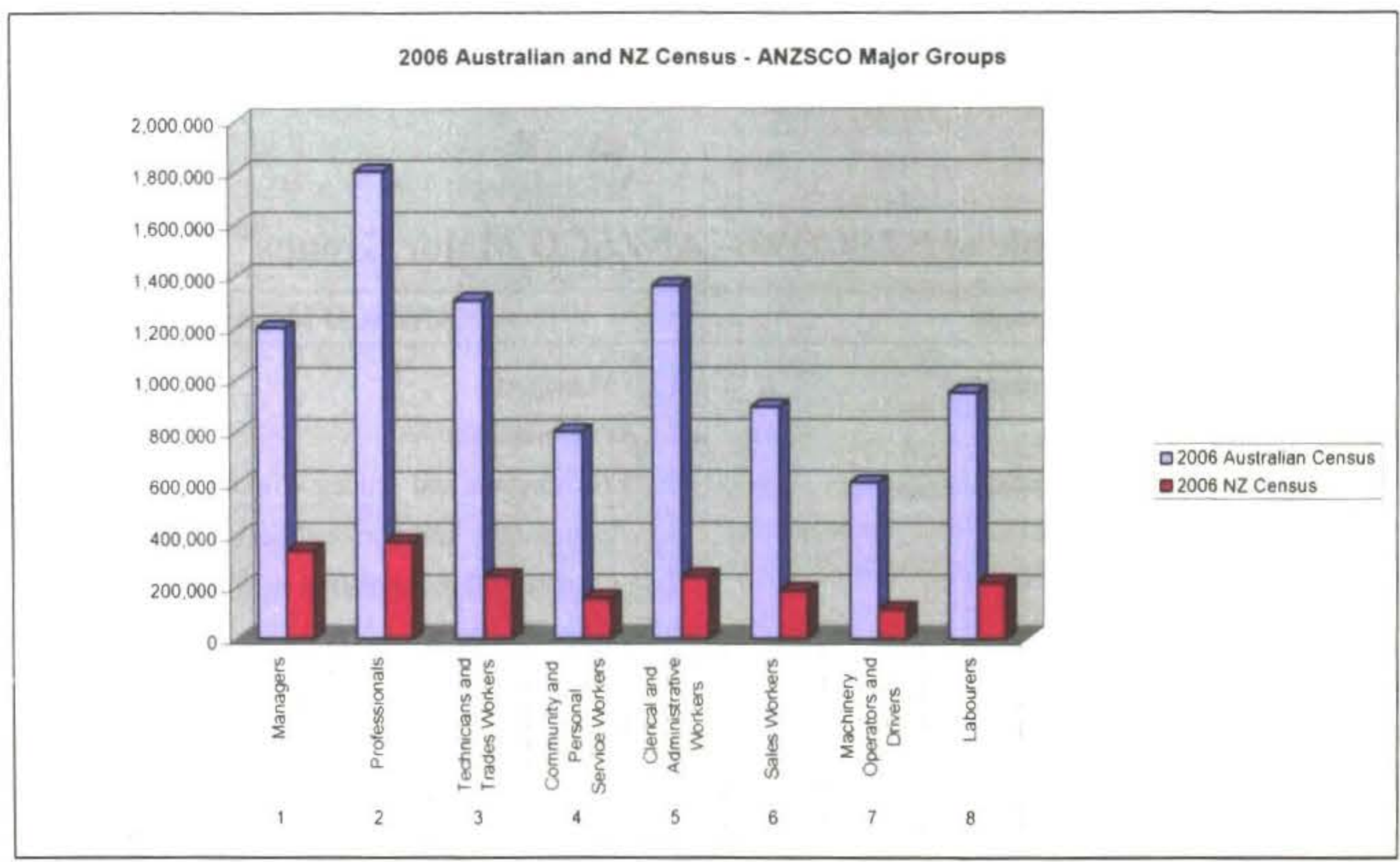


Appendix 4: 2006 Australian and New Zealand Census data by ANZSCO Major Groups (excluding Residual Categories) - Percentage Comparison

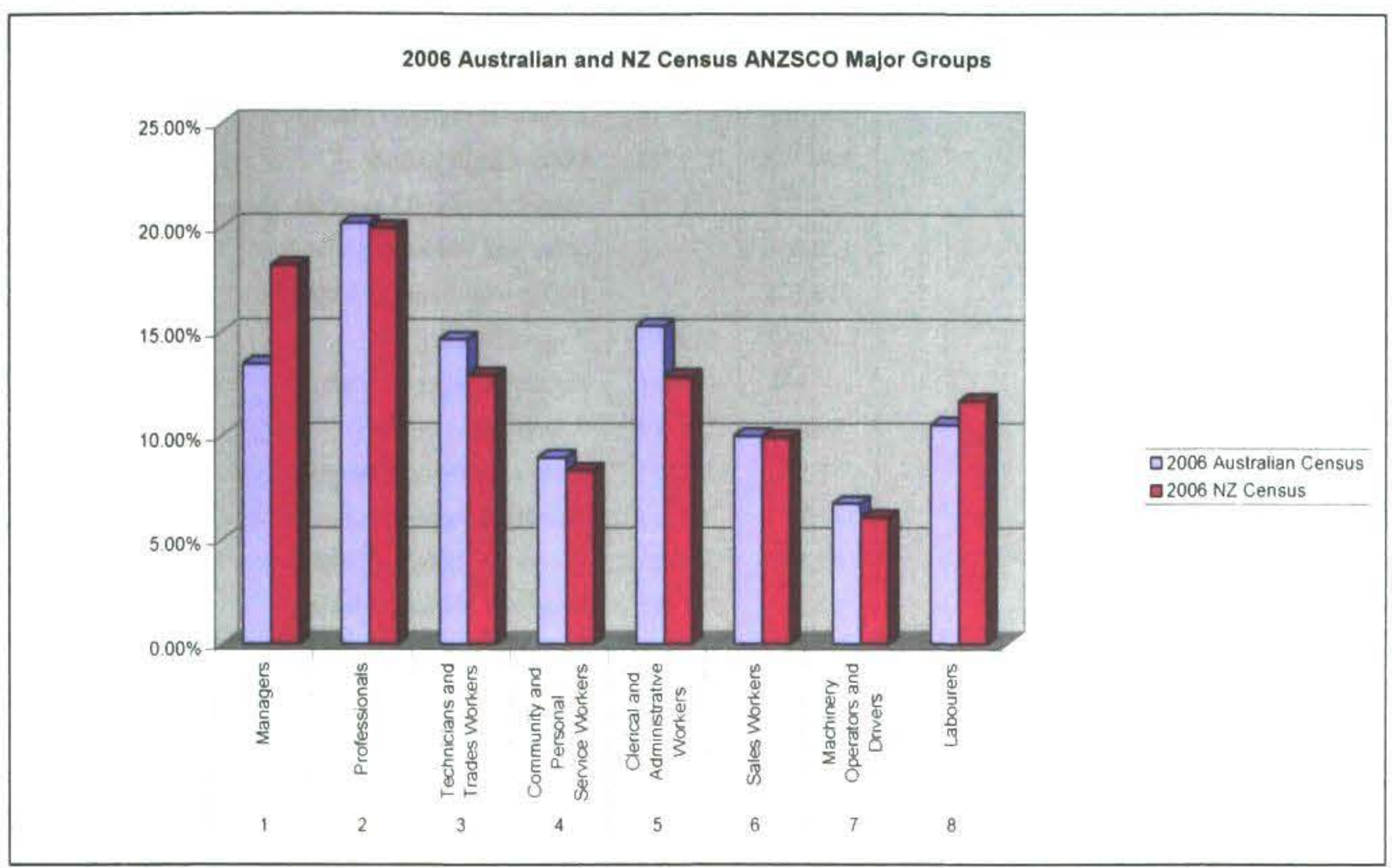

Appendix 5: Intercensal Count by NZSCO99 Major Group

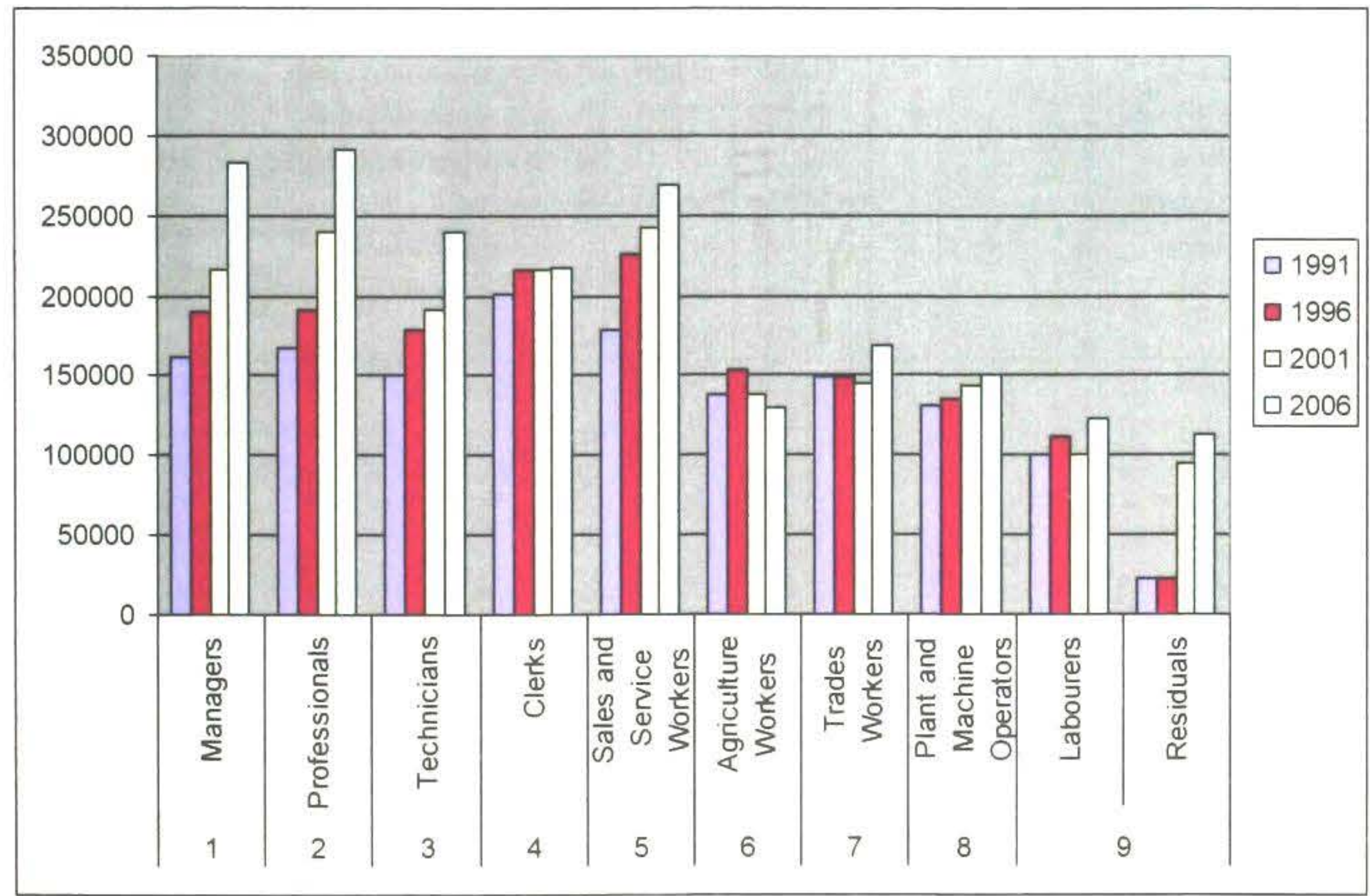


Appendix 6: 2006 Australian and New Zealand Top Thirty Occupations (sorted by ANZSCO Occupation code)

\begin{tabular}{|c|c|c|c|c|c|}
\hline \multicolumn{3}{|c|}{2006 Australian Top Thirty Occupations and Counts } & \multicolumn{3}{|c|}{2006 New Zealand Top Thirty Occupations and Counts } \\
\hline 111111 & Chief Executive or Managing Director & 46,432 & 111111 & Chief Executive or Managing Director & 38,127 \\
\hline 131112 & Sales and Marketing Manager & 79,190 & 111211 & Corporate General Manager & 28,971 \\
\hline 142111 & Retail Manager (General) & 179,328 & 121313 & Dairy Cattle Farmer & 21,501 \\
\hline 221111 & Accountant (General) & 112,793 & 121411 & Mixed Crop and Livestock Farmer & 12,408 \\
\hline 241213 & Primary School Teacher & 126,056 & 131112 & Sales and Marketing Manager & 23,307 \\
\hline 241411 & Secondary School Teacher & 118,672 & 132411 & Policy and Planning Manager & 18,435 \\
\hline 254499 & Registered Nurses nec & 47,830 & 133112 & Project Builder & 26,082 \\
\hline 323211 & Fitter (General) & 54,144 & 142111 & Retail Manager (General) & 32,946 \\
\hline 331212 & Carpenter & 76,877 & 221111 & Accountant (General) & 20,799 \\
\hline 351311 & Chef & 44,555 & 241111 & Early Childhood (Pre-primary School) Teacher & 13,728 \\
\hline 391111 & Hairdresser & 47,877 & 241213 & Primary School Teacher & 27,375 \\
\hline 421111 & Child Care Worker & 59,471 & 241411 & Secondary School Teacher & 21,183 \\
\hline 431111 & Bar Attendant & 47,748 & 254418 & Registered Nurse (Medical) & 21,198 \\
\hline 431511 & Waiter & 86,133 & 321211 & Motor Mechanic (General) & 14,388 \\
\hline 511112 & Program or Project Administrator & 71,179 & 341111 & Electrician (General) & 13,491 \\
\hline 512111 & Office Manager & 92,275 & 351311 & Chef & 12,909 \\
\hline 521111 & Personal Assistant & 44,029 & 423313 & Personal Care Assistant & 28,239 \\
\hline 521211 & Secretary (General) & 81,918 & 431511 & Waiter & 13,563 \\
\hline 531111 & General Clerk & 206,290 & 512111 & Office Manager & 17,382 \\
\hline 541211 & Inquiry Clerk & 51,156 & 531111 & General Clerk & 55,548 \\
\hline 542111 & Receptionist (General) & 79,950 & 542111 & Receptionist (General) & 24,336 \\
\hline 551111 & Accounts Clerk & 80,164 & 551111 & Accounts Clerk & 19,179 \\
\hline 551211 & Bookkeeper & 77,561 & 552111 & Bank Worker & 11,589 \\
\hline 552111 & Bank Worker & 54,332 & 611399 & Sales Representatives nec & 39,126 \\
\hline 621111 & Sales Assistant (General) & 442,895 & 621111 & Sales Assistant (General) & 87,351 \\
\hline 631111 & Checkout Operator & 86,213 & 733111 & Truck Driver (General) & 25,548 \\
\hline 733111 & Truck Driver (General) & 121,020 & 741111 & Storeperson & 18,330 \\
\hline 811211 & Commercial Cleaner & 112,609 & 811211 & Commercial Cleaner & 30,126 \\
\hline 851311 & Kitchenhand & 86,359 & 841611 & Mixed Crop and Livestock Farm Worker & 15,792 \\
\hline 891211 & Shelf Filler & 51,105 & 899999 & Labourers nec & 32,385 \\
\hline
\end{tabular}

